\title{
Metacognitive Skills as Predictors of Cognitive Failure
}

\author{
Salem Ali Salem Algharaibeh \\ Department of Psychology, Qassim University, Buraidah, Kingdom of Saudi Arabia
}

Email address:

gharaibeh_salem@yahoo.com, graiebh@qu.edu.sa

\section{To cite this article:}

Salem Ali Salem Algharaibeh. Metacognitive Skills as Predictors of Cognitive Failure. American Journal of Applied Psychology. Vol. 6, No. 3, 2017, pp. 31-37. doi: 10.11648/j.ajap.20170603.11

Received: May 12, 2017; Accepted: May 22, 2017; Published: July 10, 2017

\begin{abstract}
This research aimed at identifying the levels of metacognitive skills (planning, monitoring, and assessment), cognitive failure, the differences in them according to specialisations (scientific college and literary college), and the predictive ability of metacognitive skills in detecting cognitive failure. The metacognitive skills questionnaire (MCSQ) and cognitive failure questionnaire (CFQ) were applied to 241 female students from Qassim University in Saudi Arabia. It was found that these students have high level of planning, low level of monitoring and assessment, and low level of cognitive failure. Next, it was revealed that there were statistically significant differences in planning and monitoring skills according to specialisations in favour of scientific colleges, and statistically significant differences in cognitive failure in favour of literary colleges. Also, cognitive failure could be inversely predicted by planning and monitoring.
\end{abstract}

Keywords: Cognitive Failure, Metacognitive Skills, Undergraduate Students

\section{Introduction}

Cognitive failure has been linked to a number of areas, such as cognitive psychology, developmental psychology, educational psychology, and neuropsychology since its first appearance, when Freud presented an analysis and explanation of the possible causes of performance failures in his book, "The Psychology of Everyday Life" [1, 2, 3]. Recently, attention has shifted to cognitive failure that occurs during the performance of a task normally performed by the individuals $[4,5]$.

Cognitive failure is defined as the possible outcome of a general failure in a system of cognitive control. For example, when attention is diverted from the current task and is focused on other stimuli because of the dispersion of ideas as a result of external or internal dispersions, such as dreams [1]. Reason [3] noted that the absence of cognitive controls can lead to an increase in the frequency of cognitive failure.

Forgetfulness may occur in the memory due to automatic decay, where fading sensory occurs over time. Even if individuals are not exposed to new sensory inputs, interference displacement in the memory could play a prominent role in losing information. Failure to treat it, as a result of exposure to new stimuli, may cause information to overlap or being replaced with the new one. These processes occur subliminally, therefore, the individuals are not fully aware of what was happening to them. Thus, they would not be able to use any control strategies to maintain information or to prevent their disappearance [6]. The perceptual system does not process massive stimuli and information coming in at every moment. It has a limited capacity, and therefore, requires some type of filtering and selection of stimuli [7].

One important reason for studying cognitive failure is that it is not just a repetition of errors according to individual differences, neurological disorders, and age, but it extends to what may result from accidents in daily life [3]. For example, forgetting to take down the landing stick before landing the plane may lead to an actual disaster and the loss of hundreds of lives. Therefore, the study of cognitive failure would not only provide better understanding of the basic mechanisms that could lead to such errors, but also to provide better understanding of who are vulnerable for the occurrence of such errors [8].

Neisser [9] pointed out that cognitive processes must be treated as requiring extensive research into their nature, importance, characteristics, and their interactions with other processes, which link them with the components of other personalities, such as emotional, social, and physical 
components.

Several studies have dealt with cognitive failure in relation to different variables, such as indecisiveness, fluid intelligence, and personality traits [10], learning progress [11], psychological stress [12], self-efficacy, learning interest, and satisfaction with social media learning [13], alexithymia and predicting high-risk behaviours [14], unsafe behaviours and accidents [15], aging [16], educational self-regulation strategies [17], metacognitive beliefs [16, 18], metacognitive strategies [19], metacognition components [20, 21], as well as metacognitive failures in mathematics [22].

Flavell [23] defined metacognitive thinking as the awareness or knowledge of learners about their cognitive processes, outputs, and related knowledge. Swanson and Torhan [24] identified metacognitive thinking as individuals' awareness and control of their cognitive processes in learning. Meanwhile, Zachary [25] defined it as knowledge about Knowledge. Nonetheless, Hacker [26] and Garner [27] pointed out that the concept of metacognition is still unclear, and its most prominent characteristic is that it involves being aware of specific thinking processes and procedures.

Metacognition is a state where individuals are thinking about their thinking and their knowledge of themselves. For example, to identify what they know, what they have learned, and what they could do to improve learning and achievement in general [28]. Metacognitive skills include planning, monitoring, and assessment skills that help students to focus on task-related information to build enough understanding and representation of the task [29]. In this sense, students are able to self-learn, have better awareness of their thinking, as well as design their work plans, monitor the implementation, and assess those plans [30].

Graham [31] pointed out that cognitive thinking learners use discovery strategies to discover what they need to learn before coming up with deeper knowledge and better performance because metacognitive strategies allow them to plan, control, and assess their learning. Wallach and Miller [32] argued that individuals' understanding and conscious thinking of the mechanisms they perform allow them to spend less time and effort to accomplish their goals.

Otero, Campanario, and Hopkins [33] posited that the level of metacognitive thinking among students in humanities was better than among students in scientific colleges. Cognitive failure is associated with metacognition, in which metacognition is involved in assessment, monitoring, and cognitive control [18]. Therefore, metacognitive is able to control the beliefs that are linked with cognitive failure. Cognitive failure is a cognitive slip or error appeared in the memory, attention, and action. The components of metacognitive include control, positive beliefs about worry, confidence, and negative beliefs about the uncontrollability of thoughts. These are all related with cognitive failure [19]. Barati and Oreyzi [20] found that there was a significant discrepancy between two groups (with accident and without accident), in terms of cognitive failure and metacognitive components. Additionally, the relationship between cognitive failure and meta-cognitive components was significant in the two groups.

Elderly people reported a relatively lower frequency of cognitive failure compared to young people, while those having a relatively higher frequency of cognitive failure stated that they carefully monitor their cognitive activities. However, this result was independent of age. Paradoxically, elderly people are often claimed to have remarkable worries about their own cognitive abilities, and they seem unable to record the cognitive lapses that are known to become more frequent with aging [16].

\section{Research Objectives}

The present study aimed to examine the relationship between metacognitive skills and cognitive failure among university students, to determine the levels of metacognitive skills and cognitive failure, to determine whether there were any significant differences in metacognitive skills and cognitive failure according to specialisations (scientific colleges and literary colleges), and to examine whether metacognitive skills could predict cognitive failure among the Qassim University students by answering the following research questions.

\section{Research Questions}

Question 1: What are the levels of metacognitive skills (planning, monitoring, and assessment) among university students?

Question 2: What is the level of cognitive failure among university students?

Question 3: Are there any significant differences in metacognitive skills (planning, monitoring, and assessment) according to specialisations (scientific colleges and literary colleges) among university students?

Question 4: Are there any significant differences in cognitive failure according to specialisations (scientific colleges and literary colleges) among university students?

Question 5: Can the cognitive failure be predicted by metacognitive skills (planning, monitoring, and assessment) among university students?

\section{Research Method}

\subsection{Population, Participants, and Procedure}

The population of this study involved the Qassim University students in the Kingdom of Saudi Arabia (KSA). The sample consisted of 241 female students, who were selected at random. These participants were attending their first year at Qassim University in KSA. With regards to specialty, $126(52.28 \%)$ of the participants were from scientific colleges, and $115(47.71 \%)$ of them were from literary colleges. The participants ranged in age, from 18 to 19 years old $(\mathrm{M}=18.71, \mathrm{SD}=0.81)$. Measures were administered to the sample in the first semester of the academic year of 2016/ 2017. 


\subsection{Measures}

\subsubsection{Metacognitive Skills Questionnaire}

The metacognitive skills questionnaire (MCSQ) [34] in the Saudi environment was used to evaluate three metacognitive skills (planning, monitoring, and assessment). The questionnaire has 31 items consisting of response options in a three-point Likert scale format, ranging from $1=$ never, to 3 = very often. The reliability coefficient of the MCSQ was good: alpha between 0.75 and 0.88 .

\subsubsection{Cognitive Failure Questionnaire}

The cognitive failure questionnaire (CFQ) [4] in the Saudi version by El Far and El Subaie [35] was used to evaluate perceived cognitive failure. The questionnaire has 25 items which consist of response options in a five-point Likert scale format, ranging from $0=$ never, to $5=$ very often. The reliability coefficient for the Saudi version of the CFQ was good: alpha $=0.89$.

\subsubsection{Measures Reliability}

Table 1 shows that the study measures have acceptable degrees of alpha coefficients.

Table 1. Alpha coefficients for MCSQ and CFQ.

\begin{tabular}{ll}
\hline Measure & Alpha Coefficient \\
\hline Planning & 0.79 \\
Monitoring & 0.76 \\
Assessment & 0.81 \\
Cognitive failure & 0.84 \\
\hline
\end{tabular}

\section{Results}

Question 1: What are the levels of metacognitive skills (planning, monitoring, and assessment) among university students?

In order to answer this question, the mean and standard deviation values of the study sample performance were calculated based on the metacognitive skills questionnaire used in this study, to apply the one sample t-test, as shown in Table 2 .

Table 2. Descriptive Statistics and One Sample t-test of the study sample performance on MCSQ.

\begin{tabular}{lllllll}
\hline Metacognitive Skills & Test Value & Mean & Std. Deviation & N & Df & t \\
\hline Planning & 24 & 17.38 & 1.95 & 241 & 240 & -52.583 \\
Monitoring & 20 & 26.76 & 1.49 & 241 & 0.000 & 240 \\
Assessment & 16 & 10.09 & 0.75 & 241 & 240 & 70.237 \\
\hline
\end{tabular}

In Table 2, the test value for planning skill was 24, and the mean of the study's sample responses to the questionnaire was 17.38 , with standard deviation of 1.95 . It was also observed that the $t$ value was -52.583 . This means that there were significant differences $(p$-value $=0.000 ; \mathrm{df}=240)$ in favour of the test value. Since the mean of the study sample performance was less than the test value, this implied that the level of planning skill among the study sample was low.

Table 2 also shows that the test value for monitoring skill was 20 , and the mean of the study's sample responses to the questionnaire was 26.76, with standard deviation of 1.49 . Meanwhile, the $t$ value was 70.237 . This means that there were significant differences $(p$-value $=0.000 ; \mathrm{df}=240)$ in favour of the mean performance of the study sample. Since the mean of the study sample performance was higher than the test value, this implied that the level of monitoring skill among the study sample was high.
As for the assessment skill, Table 2 shows that the test value for this skill was 16 , and the mean of the study's sample responses on the subscale was 10.09 , with standard deviation of 0.75 , and $t$ value that equals -121.857 . This means that there were significant differences $(p$-value $=$ $0.000 ; \mathrm{df}=240$ ) in favour of the test value. Since the mean of the study sample performance was less than the test value, this implied that the level of assessment skill among the study sample was low.

Question 2: What is the level of cognition failure among university students?

In order answer this question, the mean and standard deviation values of the study sample performance were calculated based on the cognitive failure questionnaire used in this study, to apply the one sample t-test between the performance mean of the sample and the test value of the questionnaire, as shown in Table 3.

Table 3. Descriptive statistics and one sample t-test of the sample performance on CFQ.

\begin{tabular}{lllllll}
\hline & Test Value & Mean & Std. Deviation & N & Df & t \\
\hline Cognitive failure & 50 & 27.03 & 2.84 & 241 & 240 & -125.103 \\
\hline
\end{tabular}

Table 3 shows that the test value for cognitive failure was 50 , and the mean of the study's sample responses on the questionnaire was 27.03 , with standard deviation of 2.84 . It was also observed that the $t$ value was -125.103 . This means that there were significant differences ( $p$-value $=0.000 ; \mathrm{df}=$ 240) in favour of the test value. Since the mean of the study sample performance was less than the test value, this can be interpreted that the level of cognitive failure among the study sample was low.

Question 3: Are there significant differences in metacognitive skills (planning, monitoring, and assessment) according to specialisations (scientific colleges and literary colleges) among university students? 
Table 4. Independent sample t-tests between scientific college and literary college responses on MCSQ.

\begin{tabular}{lllll}
\hline Metacognitive Skills & F & T & df & Sig. (2-tailed) \\
\hline Planning & 13.29 & 3.188 & 239 & 0.002 \\
Monitoring & 48.67 & 8.591 & 239 & 0.000 \\
Assessment & 3.91 & -0.942 & 239 & 0.347 \\
\hline
\end{tabular}

In order to examine the differences in planning between the two groups (scientific - literary colleges), an independent sample $t$-test was conducted, where $\mathrm{F}=13.29$. The results indicated that there was a significant difference in planning observed between the two groups $(\mathrm{t}=3.188$, p-value $=$ $0.002)$. These results suggested that the individuals in the scientific college group $(\mathrm{m}=17.76$; $\mathrm{sd}=2.072)$ have higher levels of planning than the individuals in the literary college group $(\mathrm{m}=16.97$; $\mathrm{sd}=1.73)$.

In order to examine the differences in monitoring between the two groups (scientific colleges and literary colleges), an independent sample t-test was conducted, where $\mathrm{F}=48.67$. The results of this test indicated that there was a significant difference in monitoring observed between the two groups $(\mathrm{t}$ $=8.591, \mathrm{p}$-value $=0.000)$. These results suggested that the individuals in the scientific college group $(\mathrm{m}=27.46$; $\mathrm{sd}=$ 1.53) have higher levels of monitoring than the individuals in the literary college group $(\mathrm{m}=26.01 ; \mathrm{sd}=1.004)$.

In order to examine the differences in the assessment between the two groups (scientific colleges and literary colleges), an independent sample t-test was conducted, where $\mathrm{F}=3.91$. The results of this test indicated that there was no significant difference in the assessment observed between the two groups $(\mathrm{t}=-0.942$, $\mathrm{p}$-value $=0.347)$. These results suggested that the individuals in the scientific college group $(\mathrm{m}=10.05 ; \mathrm{sd}=0.73)$ and the individuals in the literary college group $(\mathrm{m}=10.14 ; \mathrm{sd}=0.78)$ showed no significant differences in assessment.

Question 4: Are there significant differences in cognitive failure according to specialisations (scientific colleges and literary colleges) among university students?

Table 5. Independent sample t-tests between scientific and literary college responses on $C F Q$.

\begin{tabular}{lllll}
\hline & F & T & df & Sig. (2-tailed) \\
\hline Cognitive failure & 13.89 & -5.391 & 239 & 0.000 \\
\hline
\end{tabular}

In order to examine the differences in cognitive failure between the two groups (scientific and literary colleges), an independent sample t-test was conducted, where $\mathrm{F}=13.89$. The results indicated that there was a significant difference in cognitive failure observed between the two groups $(\mathrm{t}=$ 5.391, p-value $=0.000$ ). This result suggested that the individuals in the literary college group $(\mathrm{m}=28.02$; $\mathrm{sd}=$ 2.16) have higher levels of cognitive failure than the individuals in the scientific college group $(\mathrm{m}=26.14$; $\mathrm{sd}=$ 3.10).

Question 5: Can cognitive failure be predicted by metacognitive skills (planning, monitoring, and assessment) among university students?

In order to answer this question, a simple regression analysis was performed using the enter method to determine the independent variables' ability (planning, mentoring, and assessment) to predict the dependent variable (cognitive failure), as shown in Table 6 .

Table 6. Results of the analysis of variance for the regression model.

\begin{tabular}{lllllll}
\hline Model & $\begin{array}{l}\text { Sum of } \\
\text { Squares }\end{array}$ & df & $\begin{array}{l}\text { Mean } \\
\text { Square }\end{array}$ & F & Sig. & $\mathbf{R}^{\mathbf{2}}$ \\
\hline Regression & 470.874 & 3 & 156.958 & 25.17 & 0.000 & \\
Residual & 1477.790 & 237 & 6.235 & & & 0,242 \\
Total & 1948.664 & 240 & & & & \\
\hline
\end{tabular}

Table 6 shows that the total regression model has succeeded in predicting cognitive failure significantly $(\mathrm{F}=$ 25.17), and the value of the explained variance by the independent variables (planning, mentoring, and assessment) was $\mathrm{R}^{2}=0.242$.

Table 7 shows the crude and standard regression coefficients of the regression model and its statistical significances.

Table 7. Simple regression analyses for metacognitive skills (planning, monitoring, and assessment) in predicting cognitive failure $(N=241)$.

\begin{tabular}{llllll}
\hline Variable & B & $\boldsymbol{\beta}$ & t & Sig. & $\mathbf{R}^{\mathbf{2}}$ \\
\hline Constant & 53.305 & --- & 12.450 & 0.000 & \\
Planning & -0.23 & -0.16 & -2.747 & 0.006 & 0.242 \\
Monitoring & -0.83 & -0.44 & -7.531 & 0.000 & \\
Assessment & 0.01 & 0.004 & 0.061 & 0.951 & \\
\hline
\end{tabular}

From Table 7, it is clear that monitoring was the most predictive skill for cognitive failure among University of Qassim students $(\beta=-0.44)$, followed by planning, which could also predict cognitive failure significantly $(\beta=-0.16)$. Meanwhile, the assessment was unable to predict cognitive failure significantly. Accordingly, the regression relationship can be formulated as follows:

Raw regression equation:

- Cognitive failure $=53.305-0.23$ (planning) - 0.83 (monitoring).

Standard regression equation:

- Cognitive failure $=$ - 0.16 (planning) - 0.44 (monitoring).

\section{Discussion and Conclusion}

This study aimed to determine the levels of metacognitive skills and cognitive failure, to determine whether there were significant differences in metacognitive skills (planning, monitoring, and assessment) and cognitive failure according to specialisations (scientific colleges and literary colleges), and to examine if metacognitive skills could predict cognitive failure among the students at the University of Qassim. This study found that there was a high level of planning skill. This finding was in line with the results of Al-Jarrah and Obeidat 
[36], in which they found high levels of metacognitive skills among university students. Nonetheless, these results differed with the results of other studies [37, 38, 39, 40], which discovered that the levels of metacognitive thinking skills were only at the moderate level.

This high level of planning skill can be explained by the fact that the sample of the present study consisted of first year students at the university. Since university experiences differ from school experiences, experiencing this new world would have required proper planning based on logical scientific bases. Therefore, most of the attention of these first year students may have been on adapting to university life through planning, organising, and making friends and positive relationships with colleagues, as well as with faculty members. They would also have needed to plan on getting to know university facilities, such as the libraries, laboratories, as well as lecture halls and rooms to ensure suitable environment for success. The level of maturity, abstract thinking, and logical thinking also play different roles in acquiring planning skill - a skill that university students cannot dispense with, so that they can organise and plan their study requirements in such a way that they can succeed in it.

This study also found low levels of monitoring and assessment skills. These results differed from the results of Al-Jarrah and Obeidat [36] who found high levels of metacognitive skills among university students. On the other hand, the results of Al-Saleem et al. [40], Abu Alia and AlWahr [37], Al-Khuzam [38], and Al-Mutairi [39] showed that the levels of metacognitive thinking skills were at the moderate level. The low levels of monitoring and assessment skills can also be explained by the fact that the sample of this study consisted of first year students at the university. Therefore, they might have not developed their metacognitive skills, which require a pattern of complex and higher level of thinking.

Since the sample of this study consisted of first year students, who have yet to acquire a lot of academic work that must be monitored and assessed, it makes sense that they only need to focus on planning at the beginning of any work. After some time, their focus on monitoring and assessing would need to increase, which could be studied in future researches.

This study had found a low level of cognitive failure, which might be due to the nature of the chosen sample (first year students). This could mean that these students were still at the beginning of their university stage; they only feel the joy and pleasure of joining the university, and they have high hopes and positive aspirations for the future. They are not thinking much about graduating, and the stress of low achievement and fear of academic failure. These may be reflected by their feeling of comfort, and thus, of not falling into cognitive failures.

The low levels of cognitive failure might also be due to the fact that first year students are not exposed to too much stress, either at the university or at home. Female students do not have many burdens and responsibilities like the male students, especially if the conservative nature of the Saudi society is taken into consideration, which places most of the responsibilities on males. Islam also honours females by granting them various rights, where females rely heavily on the family (their fathers and brothers) for all their needs. They do not have to worry about working to fulfil their needs and expenses. The Islamic religion has placed these responsibilities upon the males. Thus, female students are not compelled to think about these things, which make them more stable psychologically, intellectually, and emotionally. This stability may reflect on the females' ability to focus more, and not to fall into cognitive failures.

In addition, a part of the low level of cognitive failure could be attributed to another sample trait. The average age of the study sample was $(\mathrm{m}=18.71, \mathrm{sd}=0.81)$, which was still in adolescent years. This means that the students at this age still have the ability to focus on performing the tasks required, and they would also have good memories, which would have helped them avoid making mistakes and cognitive failures. This study also found that there were significant differences in planning and monitoring skills, in favour of students in scientific colleges. This could mean that students in scientific colleges have better planning and monitoring skills compared to the students in literary colleges. This observation was on line with the results obtained by Elsayed [34], whereby she found evidence of the superiority of scientific female students in planning and monitoring. Nonetheless, Al-Saleem et al. [40] concluded that there were no significant differences in planning, monitoring, and assessment according to specialisations.

The results of this study had also differed from the results obtained by Otero et al. [33], who found that the levels of metacognitive skills among students in humanities were better than among students from scientific colleges. The findings of Al-Jarrah and Obeidat [36] showed statistically significant differences in the regulation of cognition due to academic specialisation, which favoured humanities students. This result can be explained in light of the fact that students of scientific colleges may have developed the ability to plan their learning and control its steps more than students of literary colleges. This is because they are also expected to have higher levels of logical and abstract thinking by virtue of the nature of their specialisation.

These results could also be attributed to the nature of the scientific courses that require higher levels of thinking, cognitive, and metacognitive skills, such as planning and monitoring. The nature of curricula in these colleges require students to understand, analyse, plan, monitor, and develop other higher cognitive processes, more than for students in literary colleges, in which their study depend mostly on indoctrination and memory, rather than analysis, planning, and assessment. Thus, students in literary schools are more dependent on minimal mental processes, such as memorisation. In addition, teaching methods in scientific colleges, which are more suitable for higher mental skills, such as planning and monitoring, might also play a role in the superiority of students in scientific colleges, in terms of their planning and monitoring skills. 
These results also showed that literary college students have higher levels of cognitive failure compared to scientific college students. This difference can be explained by the fact that scientific college students need to be more careful about their attention and concentration, as well as planning and implementation during their lessons because doing the opposite may cause them to lose some important information. For example, a student in a science or mathematics lesson needs to be constantly attentive because missing any of the solution steps of the issue or theory could lead to inability to understand and assimilate well. Meanwhile, students in a theoretical lecture can compensate any missing step by studying alone from books or references. Hence, students from scientific colleges are expected to be more focused, attentive, planned, organised, and in control. All these attributes could lead to lower levels of cognitive failure compared with students from literary colleges.

In addition, this study found that planning and monitoring can inversely predict cognitive failure statistically. In other words, the higher the responses of the sample to these skills, the lower the level of cognitive failure will be. This finding was in line with the outcome of the study by Mecacci and Righi [16], who found an inverse relationship between cognitive failure and monitoring. The findings in this study were partly in line with El farr and El Subaie [35], whose findings showed that planning skills can predict cognitive failure statistically. These results are logical, especially if metacognition is viewed as a mental behaviour used by individuals to organise their ideas, arrange and plan them in a systematic way, to monitor these ideas, and to make judgments about the decisions taken [40]. Meanwhile, the concept of cognitive failure is viewed as the types of falls and errors in the performance of daily tasks [4].

It would make sense that individuals who have the ability to plan proper actions, set specific goals, organise time, set priorities, and follow these effective strategies to monitor the implementation of their pre-prepared plans to achieve their goals, would be able to avoid making mistakes and falling into cognitive failures while performing their daily tasks. Individuals could have committed errors and mistakes for various reasons, such as bad planning, poor regulation and control, lack of clarity of goals, lack of priority setting, and the absence of appropriate strategies for the implementation of their plans. Therefore, lapses and cognitive failures would decline when metacognitive skills are at higher levels.

\section{Research Limitations}

Although the results of this study appeared promising, some limitations must be pointed out; for example, the impossibility of generalizing the results beyond the specific sample of Saudi female students used in this current study. Another limitation is that the sample consisted only of first year university students. Future researches should use samples that are more widely representative of the Saudi population, and the results of other international studies should also be studied and compared.

\section{References}

[1] Reason, J. T. (1984). Lapses of attention in everyday life. In R. Parasuraman \& D. R. Davies (Eds.), Varieties of attention. Orlando, Florida: Academic Press.

[2] Reason, J. T. (1987). Cognitive aids in process environments: prostheses or tools? International Journal of Man-Machine Studies, 27, 463-470.

[3] Reason, J. T. (1990). Human error. New York: Cambridge University Press.

[4] Broadbent, D. E., Cooper, P. F., FitzGerald, P., \& Parkes, K. R. (1982). The cognitive failures questionnaire (CFQ) and its correlates. British Journal of Clinical Psychology, 21 (1), 116. DOI: 10.1111/j.2044 8260.1982.tb01421.x.

[5] Elfferich, M. D., Nelemans, P. J., Ponds, R.W., De Vries, J., Wijnen, P. A., \& Drent, M. (2010). Everyday cognitive failure in sarcoidosis: the prevalence and the effect of anti-TNFalpha treatment. Respiration, 80 (3), 212-219.

[6] Ashcraft, M. (1989). Human Memory and Cognition. New York: Harper Collins Publisher.

[7] Broadbent, D. E. (1957). A mechanical model for human attention and immediate memory.Psychology Review, 64 (3), 205-215. doi.org/10.1037/h0047313.

[8] Wallace, J. C. (2004). Confirmatory factor analysis of the cognitive failures questionnaire: evidence for dimensionality and construct validity. Personality and Individual Differences, 37, 307-324. doi.org/10.1016/j.paid.2003.09.005.

[9] Neisser, U. (1967). Cognitive Psychology. New York: Appleton - Century- Crofts.

[10] Di Fabio, A., \& Palazzeschi, L. (2013). Incremental variance in indecisiveness due to cognitive failure compared to fluid intelligence and personality traits. Personality and Individual Differences, 54 (2013), 261-265.

[11] Hong, J., Tai, K., Hwang, M., \& Kuo, Y. (2016). Internet cognitive failure affects learning progress as mediated by cognitive anxiety and flow while playing a Chinese antonym synonym game with interacting verbal-analytical and motorcontrol. Computers and Education, 100, 32-44.

[12] Day, A., Brasher, K., \& Bridger, R. (2012). Accident proneness revisited: the role of psychological stress and cognitive failure. Accident Analysis and Prevention, 49, 532535 .

[13] Hong, J., Hwang, M., Szeto, E., Tsai, C., Kuo, Y., \& Hsu, W. (2016). Internet cognitive failure relevant to self-efficacy, learning interest, and satisfaction with social media learning. Computers in Human Behavior, 55, 214-222.

[14] Abbasi, M., Bagyan, M., \& Dehghan, H. (2014). Cognitive failure and alexithymia and predicting high-risk behaviours of students with learning disabilities. International Journal of High Risk Behaviour Addict. 3 (2), 1-6. doi: 10.5812/ijhrba.16948.

[15] Rangi, N., Farshad, A., Khosravi, Y., Zare, G., \& Mirkazemi, R. (2014). Occupational cognitive failure and its relationship with unsafe behaviours and accidents. International Journal of Occupational Safety and Ergonomics (JOSE), 20 (2), 265-271. 
[16] Mecacci, L., \& Righi, S. (2006). Cognitive failures, metacognitive beliefs and aging. Personality and Individual Differences, 40 (7), 1453-1459.

doi.org/10.1016/j.paid.2005.11.022.

[17] Veysi, N., Taghinezhad, A., Shayan, N., \& Azadikhah, M. (2015). A comparison of educational self-regulation strategies and cognitive failures in students afflicted with dysgraphia and normal students. GMP Review, 15, 69-78.

[18] Zargar, F. Mohammadi, A., Shafiei, E., \& Fakharian, E. (2015). Comparing cognitive failures and metacognitive beliefs in mild traumatic brain injured patients and normal controls in Kashan. Archive of Trauma Research, 4 (2). doi: 10.5812/atr.4(2)2015.20977.

[19] Tabatabaee, S., Sheikh, M., Malekirad, A., \& Samadi, F. (2013). Cognitive failures and metacognitive strategies of thought control in addicts and normal individuals. European Journal of Experimental Biology, 2013, 3 (6), 315-32.

[20] Barati, H., \& Oreyzi, H. (2010). Comparison of cognitive failure and metacognition components via moderator variable of job accident rate. Journal of Behavioural Sciences, 4 (2), 115- 121.

[21] Shahgholian, M., Azadfallah, P., \& Fathi-Ashtiani, A. (2012). Comparison of metacognition components and cognitive failures by personality dimensions. Journal of Behavioural sciences, 2 (2), 125-130.

[22] Nizlel, H., Subanji, Nusantara, T., Susiswo, Sutawidjaja, A., \& Rahardjo, S. (2016). University students' metacognitive failures in mathematical proving investigated based on the framework of assimilation and accommodation. Educational Research and Reviews, 11 (12), 1119-1128.

[23] Flavell, J. (1976). Metacognitive aspects of problem solving. In L. B. Resnick (Ed.), The Nature of Intelligence (pp. 231235). Hillsdale, New Jersey: Lawrence Erlbaum.

[24] Swanson, H. \& Torhan, M. (1996). Learning disabled and average readers' working memory and comprehension: does metacognition play a role? British Journal of Educational Psychology, 66 (3), 333-355.

[25] Zachary, W. (2000). Incorporating metacognitive capabilities in synthetic cognition. Proceedings of the Ninth Conference on Computer Generated Forces and Behavioural Representation, 512-513.

[26] Hacker, D. J. (2005). Metacognition: Definitions and Empirical Foundations. The University of Memphis, Retrieved March 4, 2017. From http://www.psyc.memphis.edu $\backslash$ trg $\backslash$ meta.htm.

[27] Garner, R. (1988). Metacognition and Reading Comprehension. Norwood, NJ: Ablex.

[28] Cox. M. T. (2005). Metacognition in computation: A selected research review. Artificial Intelligence, 169(2), 104-141.
[29] Veenman, M. V., \& Spaans, M. A. (2005). Relation between intellectual and metacognitive skills: Age and task differences. Learning and Individual Differences, 15, 159-176.

[30] Thamraksa, C. (2004). Metacognition, A key to success for self-learners. BU Academic Review, 4(1), 95-99.

[31] Graham, S. (1997). Effective Language Learning. Clevedon. England: Multilingual Matters.

[32] Wallach, G., \& Miller, L. (1988). Language Intervention and Academic Success. Boston: M. A. College Hill Press.

[33] Otero, J., Campanario, J., \& Hopkins, K. (1992). The relationship between academic achievement and metacognitive comprehension monitoring ability of Spanish secondary school students. Educational and Psychological Measurement, 52 (2), 419-430.

[34] El-Sayed, M. (2012). Effectiveness of thinking skills development course in acquiring metacognitive skills and developing the ability of creative thinking of the university female students. Seventh Annual Arab Conference, Faculty of Specific Education in Mansoura University, 11-21 April, 651682.

[35] El Far, R. \& El Subaie, S. (2014). The predictability of cognitive executive functions and big five personality factors of cognitive failure. Arabic Studies in Psychology, 13 (1), 127.

[36] Al-Jarrah, A., \& Obeidat, A. (2011). Metacognitive thinking level amongst a sample of Yarmouk University students in the light of some variables. Jordan Journal of Educational Sciences, 7 (2), 145-162.

[37] Abu Alia, M. \& Al-Wahr M. (2000). The degree of Hashemite University students' awareness of metacognition related to preparation and submission of examinations skills and their relationships with their level, their cumulative rate and college. Dirasat: Educational Sciences, 28 (1), 1-13.

[38] Al-Khuzam, T. (2002). The degree of students' metacognition awareness in reading of science and its relationship to their sex, achievement and educational level in Mafraq. Unpublished master theses. Hashemite University: Jordan.

[39] Al-Mutairi, M. (2005). The relationship between metacognition skills awareness and reading comprehension among second secondary students in Kuwait in the light of gender and specialisation. Unpublished Master Thesis, Yarmouk University: Jordan.

[40] Al-Saleem, B., Al-Rbabaah, J., \& Al-Khawaldeh, K. (2012). The degree of acquiring metacognitive skills and its relationship with gender and specialisation and academic achievement in Jarash Secondary Schools. The International Interdisciplinary Journal of Education, 1 (3), 73-87. 